\title{
Examining the Academic and Personal-Social Experiences of Latina/o Children in Southeastern U.S. Rural, Burgeoning Latino Communities
}

\author{
José A. Villalba and Maria Brunelli \\ The University of North Carolina at Greensboro \\ Lucy Lewis \\ Powhatan Elementary School \\ Carrie Wachter \\ Purdue University
}

\begin{abstract}
Between the 1990 and 2000 U.S. Census several Southeastern states, largely void of a permanent Latino population prior to 1990, witnessed significantly large increases in the number of Latina/o residents, particularly in rural communities. This study was designed to ascertain the impressions of non-Latina/o teachers and school counselors working with Latina/o youngsters in elementary school settings in these communities through the use of focus group methodologies. Four general themes were identified using the Consensual Qualitative Research method of analysis: (I) Academic factors affecting Latina/o children in burgeoning communities; (II) School interventions used for addressing academic factors; (III) Latina/o children and family characteristics in burgeoning communities; and (IV) personal-socialeconomic factors impacting Latina/o children in burgeoning communities.
\end{abstract}

According to the National Center for Education Statistics (NCES) Latina/o students represent the fastest growing student group in the United States' elementary and secondary schools (2003). Between the years 1972 and 2000, the percentage of Latina/o students in public schools increased by $11 \%$, in comparison to a $2 \%$ increase by Black students (NCES, 2003). Consequently, in the year 2000, Latina/o students represented $44 \%$ of minority and $17 \%$ of all public school students in kindergarten through 12th grade (NCES, 2003). In response to this growing number of Latina/o children, research studies designed to ascertain the academic and personal/social needs of Latina/o children have been prevalent in the educational and counseling literature for several years (August \& Hakuta, 1997; Gopaul-McNicol \& Thomas-Presswood, 1998; Mejia, 1983; Zea, Diehl, \& Porterfield, 1997). However, upon review of the research literature, it becomes apparent that the majority of information related to Latina/o children is focused or based on children living in metropolitan areas with traditionally large Latina/o populations, such as cities in California, Texas, New York and Florida.

There is a great paucity of information related to Latina/o children living in rural settings. Furthermore, the literature that does exist related to Latina/o children in rural settings is primarily based on migrant or seasonal populations (Dinsmore \& Hess, 1999; Torres, 2001). Consequently, some of the more recent literature focuses on the characteristics, concerns and experiences of Latina/o families settling in areas of the United States where there previously had not been a significant Latina/o presence (Hamann, Wortham, \& Murillo, 2002; Martin, 2001). Specific examinations, however, of the rapidly increasing size of these new rural Latina/o settlements and its effect on Latina/o children are scarce at best. This study seeks to address how educators view the experiences of Latina/o children attending elementary schools in burgeoning, rural Latino communities. For the purposes of this study, the term "burgeoning, rural Latino communities" will be used to represent rural areas experiencing new, rapid and sustained growth of the Latino population. Furthermore, "Latina/o" will be used when referring to individuals who may selfclassify as "Hispanic," "Hispanic American," "Latin American,” "Chicano," "Mexican American,” etc.

\section{The Impact of Demographic Changes in Rural Settings in Southeastern United States on the Education of Latina/o Children}

Between 1990 and 2000, the Latina/o population grew at least $250 \%$ in certain Southeastern states (Hamann, Wortham, \& Murillo, 2002; Pew Hispanic Center, 2005a, b). Georgia, North Carolina, South Carolina, and Tennessee, for example, have all experienced sustained increases in Latina/o residents who, in the past, may have only transiently lived in those states (Pew Hispanic Center, 2005b). This influx of Latina/o children and families, with their own unique traits, characteristics, language, strengths, needs and experiences, has taxed schools and community agencies not familiar with Latinas/os (Wortham \& Contreras, 2002). As burgeoning rural Latino communities in these states have continued to grow, so have the academic needs of Latina/o children. Consequently, there exists a need for educators knowledgeable of the specific scholastic issues of Latina/o youth in burgeoning communities.

The No Child Left Behind Act of 2001 set very specific and rigorous academic achievement guidelines to which each U.S. state and school district is now held accountable. An integral facet of this legislation is ensuring the academic 
success of Latina/o students (President's Advisory Commission on Educational Excellence for Latino Americans, 2003). Recent data on the academic achievement of Latino students indicates that they have higher drop-out rates, lower scores on mathematics and reading achievement tests and are less likely to enroll in 4year institutions of higher education than their White peers (Torres, 2001). Specifically, Latina/o students are less likely to be enrolled in advanced math and science courses when compared to their White, Black, and Asian American peers (Livingston \& Wirt, 2004).

Formal education in the United States begins in elementary school, typically in kindergarten. Teachers and counselors are the professionals within the school setting most responsible for the academic, career and personal/social development of children (Gopaul-McNicol \& Thomas-Presswood, 1998). If rural areas with growing Latina/o communities are to effectively meet the challenges detailed in the No Child Left Behind Act of 2001, then school personnel and parents in these areas must be provided with adequate academic interventions, teaching techniques, resources, and population-specific information. However, many teachers and school counselors working with Latina/o children in these communities have reported frustration over the negative reactions from fellow colleagues, school administrators and non-Latina/o parents (Crawford, 1999; Wortham \& Contreras, 2002).

Furthermore, some paraprofessionals working in new Latino communities have experienced disapproval by teachers and administrators when attempting to use unique interventions aimed at addressing the specific academic needs of Latina/o students (Wortham \& Contreras, 2002).

\section{Purpose for the Study}

The purpose of the present study was to investigate the unique educational and personal-social development needs and experiences of Latina/o children in burgeoning Latino communities. Since elementary school teachers and school counselors contribute to the academic and personal-social development of all children, the authors believed these educators were well-suited to discuss the scholastic experiences, needs and strengths of Latina/o students enrolled in their elementary schools. Through qualitative methods, the researchers addressed the following questions: (a) what are the differences between the academic and personal-social needs of Latina/o children living in burgeoning Latino communities and their non-Latina/o peers?, and (b) what kinds of academic and personal-social interventions have teachers and school counselors in burgeoning Latino communities tried in a effort to help their Latina/o students?

This study was conducted in North Carolina, which has experienced a Latino population boom of over $400 \%$ between the 1990 and 2000 U.S. Census (n.d.). This study took place in a rural county, where the main industries are agriculture, meat processing and textiles. According to the U. S. Census (n.d.), the county chosen for this study had a Latino population of 564 in 1990 and 4,743 in 2000, an increase of $841 \%$. Consequently, the school district in this community has set up a bilingual welcome center for new, Latina/o immigrants as well as offering extensive English Language Learners (ELL) services. This study is exploratory in nature; therefore, qualitative methodology was used for collecting, analyzing, and interpreting data. For this study, researchers used the Consensual Qualitative Research (Hill, Thompson, \& Williams, 1997) method for collecting and analyzing data.

\section{Methodology \\ Participants}

Fourteen non-Latina/o educators working in a rural, burgeoning Latino community in North Carolina were recruited to participate in this study. Four of the participants identified themselves as school counselors and 10 identified themselves as teachers. Study participants worked in two elementary schools where the Latina/o student populations were larger than the state average $(56.7 \%$ and $11.0 \%$ of the student population was Latina/o compared to the state's average of 5.2\%) (NCES, 2002). Consequently, the participants in this study were of particular interest to the researchers because of their work with large numbers of Latina/o students. The participants self-nominated to participate in this study. The participating teachers and school counselors reported having 4 to 20 years of experience ( $\mathrm{M}=9.64, \mathrm{SD}=3.99)$. Of the 14 participants, one was African-American and 13 were Caucasian. Eleven of the participants were female and three were male.

\section{Procedure}

Three, 90-minute focus groups were used in this study to collect qualitative information from elementary teachers and school counselors. Participants were told of the focus groups after their school principals granted the researchers permission to present the study at a weekly faculty meeting. From this meeting, teachers volunteered to participate in the focus groups. Due to the exploratory nature of the subject matter, the researchers attempted to formulate homogenous groups of teachers and school counselors (Morgan, 1997). However, because of scheduling conflicts and logistical reasons, one of the groups was heterogeneous in nature, containing one school counselor and three teachers; the other two groups were divided into one group of three school counselors and one group of seven teachers. Participants were compensated \$30 for their efforts and light refreshments were provided during the focus groups.

All focus group sessions were recorded using a tape recorder and audiotapes. The authors transcribed all recordings. A focus group moderator's guide was developed 
for this study prior to commencing focus groups, in line with best research practices (Morgan, 1997). The questions in the moderator's guide were as follows:

1) What are the academic needs of Hispanic/Latino children in your school?

2) What have you tried in regards to improving their academic performance?

3) How effective would you say these interventions have been?

4) How different would you say the current group of Latina/o children is from past groups of Latina/o children living in this community?

5) What are the differences between the Latina/o children currently living in this community and Latina/o children living in cities?

\section{Data Analysis}

Data were analyzed using the Consensual Qualitative Research (CQR) approach (Hill, Knox, Thompson, Williams, Hess, \& Lanlay, 2005; Hill, Thompson, \& Williams, 1997). The main objective of CQR is to establish consensus in the data between researchers. This particular method of qualitative data analysis has proven useful in analyzing a wide range of psychosocial factors (Hill et al., 2003). Furthermore, CQR has been successfully used to analyze qualitative data gathered from focus groups (Hendrickson, McCarthy Veach, \& LeRoy, 2002; McCarthy Veach, Bartels, \& LeRoy, 2001)

Table 1
According to CQR, once data collection and transcription are complete, it is recommended that 3-5 research team members work together in order to establish consensus regarding common domains imbedded in the data. Consensus using CQR is achieved by having at least two researchers develop common domains from the data, while detailing the core ideas represented by the domains. In this study, the authors added an extra step of consensus by grouping the domains into general themes (topic areas). In accordance with other focus group research using CQR (Hendrickson et al., 2002; McCarthy et al., 2001), each focus group transcript was considered an individual "case." For cross-analysis purposes, all focus group transcripts (i.e., "all cases") were reviewed once domains had been established in order to determine the frequency of the domains across all transcripts. Domains that appeared in all cases were labeled as "general," while those that appeared in one or fewer cases were labeled "variant."

\section{Results}

Focus group participants expressed 248 experiences related to the academic and personal-social needs of Latina/o children. Participants' responses were organized into four general themes - presented in Table 1 with appropriate definitions - and 36 domains within the general themes. General Themes I and II refer to the academic needs of Latina/o children attending schools in burgeoning Latina/o communities. General Themes III and IV represent educators' perceptions of personal-social issues of Latina/o children from these communities. General theme, domain, and relevant examples are presented in this section.

General Themes Derived from Focus Group Transcripts

General Theme

I: Academic Factors Affecting Latina/o

Children in Burgeoning Communities
II: School Interventions Used for Addressing Academic Factors

III: Latina/o Children and Family Characteristics in Burgeoning Communities

IV: Personal-Social-Economic Factors Impacting Latina/o Children in Burgeoning Communities
Definition

School and academic factors which positively or adversely impact Latina/o children: These factors occur directly in a school setting or are directly related to school and academic performance

Academic interventions occurring in the school setting: Some interventions are formal, such as referrals and translated materials, and others are informal, such as motivation and encouragement

Latina/o characteristics which participants feel help/hinder the academic and personal-social development of Latina/o children

Factors which are not directly associated with being Latina/o, yet negatively impact the personal-social well-being of Latina/o children 


\section{General Theme I: Academic Factors Affecting Latina/o Children in Burgeoning Communities}

Academic factors affecting Latina/o children were attributed to the overall success of Latina/o children. Focus group participants indicated these types of factors as relevant to Latina/o school success when asked, "What are the academic needs of Hispanic/Latino children in your school?" Responses to this question centered on the negative experiences of Latina/o children in school as well as areas of concern for teachers and school counselors. There were six domains and related core ideas within this theme:

1) Testing bias and concerns. Teachers and school counselors (educators) indicated that Latina/o students were subject to standardized testing bias and were concerned about how children's academic success was measured using standardized tests.

2) Stress. School counselors believed that Latina/o children are stressed about their academic experiences due to the amount of work that is expected of them, while learning a new language and adjusting to a new environment.

3) Lack of resources for educators. Educators acknowledged that they had limited resources to help Latina/o children, such as inadequate knowledge of second-language acquisition theory, and inadequate time and funds to specifically address the academic needs of Latina/o students.

4) Concerns over appropriate development. Teachers and school counselors wondered if better pre-school education could help deal with apparent deficiencies in elementary school preparedness.

5) Academic concerns regarding subject difficulty. For some of their Latina/o students, educators noticed an inability to close an achievement gap between their Latina/o students and their non-Latina/o peers, particularly in the area of literacy and language arts.

6) Gap in understanding between home and school environments. Participants reported that Latina/o children operate in two somewhat mutually exclusive social systems which, in the case of many Latina/o children in burgeoning communities, do not share the same language nor customs.

\section{General Theme II: School Interventions Used for Addressing Academic Factors}

In this general theme, participants indicated what types of academic interventions, support, resources, and accommodations were made in order to facilitate the learning process and scholastic experience for Latina/o children in their schools. The eight domains and related core ideas for this theme follow.

1) Collaboration and referrals. This includes teachers collaborating with school counselors, school counselors collaborating with teachers, educators collaborating with outside agencies, and making medical and mental health referrals when necessary,

2) Individual and group counseling. These interventions were mentioned by participants as effective interventions for helping Latina/o children experiencing academic difficulties.

3) Motivation and encouragement. Educators explained their need to intrinsically and extrinsically support Latina/o students who were not performing at a sufficient academic level, particularly for the academic area of learning English,

4) Specialized educational programs and resources. Tutoring, after-school programs, study skills drills and activities, and mentors from local high schools were examples of special programs organized and administered by teachers and school counselors in order to help Latina/o children succeed in school.

5) Effective teachers. School counselors in the focus groups acknowledged the need to place Latina/o children with the best teachers, and they shared that they had seen the drawbacks of ineffective teachers who felt "stuck" or "burdened" with teaching Latina/o children.

6) Early interventions. The concept of preschool and Head Start-type programs was lauded as a helpful method for starting Latina/o children on equal academic footing with their non-Latina/o peers.

7) Latina/o-specific and area-specific academic interventions. Educators stressed the need to develop bilingual and culturally appropriate academic interventions, including reading and mathematic assignments related to what these children experience in their day-to-day lives.

8) Translators and translated materials. This was the most commonly cited academic intervention described by participants, and 
it dealt with the hiring and use of bilingual translators in addition to providing Latina/o parents with school materials and information in English and Spanish as a form of addressing the understanding gap mentioned in General Theme I.

\section{General Theme III: Latina/o Children and Family Characteristics in Burgeoning Communities}

This general theme generated the largest number of responses and the widest variety of domains. The domains and core ideas organized under this theme were focused on Latino cultural characteristics that participants believed positively or negatively influenced the academic and personal/social development of Latina/o children. The 14 domains and core ideas grouped under general theme III were.

1) Family and parental involvement. Participants mentioned the presence or absence of familial assistance with the academic and personal-social matters of Latina/o children.

2) Discipline. Educators' believed that Latina/o children in their schools and community displayed more discipline and pride in their behavior than their perception of the same in non-Latina/o children or Latina/o children in larger cities.

3) Community involvement. This refers to the strong bond, or "closeness," of the local Latino community, wherein Latinas/os stick together in times of need and assistance.

4) Religious and historical traditions. Although educators attributed the importance and prevalence of the Roman Catholic Church in the lives of Latina/o children and families, they also were concerned with the erosion of Latino historical traditions due to the small size of the Latino community and its distance from larger communities of Latinas/os.

5) Work ethic. Participants reported Latina/o children and families in their community to be very hard workers, including working the types of jobs which most individuals would consider undesirable (e.g., working late and multiple shifts in meat-processing plants; not complaining when presented with multiple mathematic drill sheets or vocabulary lists).

6) Gratefulness and appreciation. Compared to their non-Latina/o peers and urbanLatina/o peers, educators described their
Latina/o students and parents to be grateful for the assistance provided in schools.

7) Transient. Unlike the transient and migratory Latina/o families with whom educators in this community had historically dealt, the current Latina/o school and community populace is stable and integrated into the community.

8) Assimilation. Most teachers and school counselors described the success of Latina/o children and families to be connected to the rate at which they assimilate into the American culture, including English proficiency.

9) Problems in the home. Small houses and large families, parents working long hours and unsupervised play are a few of the factors participants believed impacted local Latina/o children.

10) Low parental education. Educators reported their Latina/o students' parents had a much lower level of formal education when compared to their non-Latina/o peers and urban-Latino peers, which they related to limited inroads made by the Latino community and the relative newness of their community.

11) Limited exposure. Based on participants' responses, Latina/o children in this community experienced academically and socially sheltered lives, compared to their non-Latina/o peers.

12) Bilingual education. Although some teachers touted the benefits of SpanishEnglish bilingual programs and curricula for the benefit of all children in their community, they acknowledged resistance to funding and resources for these types of initiatives.

13) Limited-English proficiency. The most common characteristic of Latina/o children enrolled in these schools was their designation as English language learners, which many educators believed was much higher in their community than municipalities with traditionally large and historical Latino communities.

14) Improvement. Regardless of Latina/o student and family characteristics which may be hindering Latina/o students' academic and personal-social development, participants believed circumstances are improving for this population. 


\section{General Theme IV: Personal-Social-Economic Factors Impacting Latina/o Children in Burgeoning Communities}

General Theme IV contains distinct factors, external to the family, capable of influencing Latina/o children's academic success and well-being. The eight domains and related core ideas included in General Theme IV follow.

1) Parental lack of resources. Participants believed limited time, income, and living space contribute to the difficulties experienced by some Latina/o children in participants' schools.

2) Population change. According to the educators, reports of racism and discrimination against Latina/o children have increased as a result of the rather sudden and dramatic Latina/o population growth.

3) Gang activity. Violence and crime related to gang activity is lower in this burgeoning Latino community compared to larger cities; however, some educators reported a marked rise in gang-related behavior (gang colors and gang signs) at the high school level.

4) Substance abuse and trafficking. Similar to reports of gang activities, focus group participants currently were not too worried about substance abuse and trafficking; however, participants were apprehensive about a potential for increased drug use and trafficking in their community, though not necessarily their school.

5) Safety. Educators reported the safe nature of the elementary school environment as contributing to enriching the academic experience of Latina/o children.

6) Technology. For the most part, Latina/o children displayed a high level of comfort and proficiency when working with computers.

7) Isolation. A small number of the educators were worried about their Latina/o children, specifically that many of their close relatives (siblings, grandparents, and aunts and uncles) live far away.

8) Emotional issues. School counselors were worried that emotional reactions related to the immigration process, familial strife and learning in an unfamiliar school environment could be negative and detrimental to Latina/o children.

\section{Cross-analysis of domains: General and Variant Domains}

Eleven domains qualified as "general” factors in that they were reported by all three focus groups. The 11 common domains were derived from General Themes I, II, and III, and included, (a) Specialized educational programs and resources, (b) Latina/o-specific and area-specific academic interventions, (c) Translators and translated materials, (d) Testing bias and concerns, (e) Concerns over appropriate development, (f) Gap in understanding between home and school environs, (g) Family and parental involvement, (h) Discipline, (i) Community involvement, (j) Assimilation, and (k) Low parental education. The remaining 25 domains were considered "variant” because they were only mentioned by one of the three focus groups. Finally, certain domains were only present in teachers' responses (Work ethic; Limited exposure; and Safety) or school counselors' responses (Collaboration and referrals; Motivation and encouragement; Effective teachers; Stress; Religious and historical traditions; Population change; Substance abuse and trafficking; Isolation; and Emotional issues).

\section{Discussion}

The common domains reported for all focus groups indicated a wide array of academic and cultural factors impacting student learning and development, in addition to a diverse collection of school-based interventions. One of the more unique and interesting factors described by educators was the "understanding gap.” Educators are typically familiar with the "achievement gap” between Latina/o children and their white peers (The Education Trust, 2003). It appears that participants in this study, however, also were concerned with the effects of the gap in communication and perceptions between Latino homes and American schools. Educators in this study believed that this gap, in addition to academic concerns related to English proficiency and school acculturation, impedes Latina/o children's academic success.

Both school counselors and teachers described several school interventions for addressing Latina/o students' performance and school adjustment, among them providing Latina/o students with academic programs specifically catered to their needs as well as the use of small group and individual counseling, in addition to securing translators and translating school-related documents. These types of interventions were organized and implemented in response to a wide range of issues, including testing bias and concerns, facilitating children's academic and personal/social development, and helping children become more comfortable in their school and surrounding community. Based on these common domains, school 
personnel are acknowledging the wide-rage of academic and personal issues their Latina/o students are experiencing. The authors were particularly intrigued by one school counselor's work to seek community involvement from the local Latino population. In this case, the school counselor realized the tight-knit nature of the Latino community and sought to bring in Latina/o adult role models, mentors, and parent volunteers to assist with school-based initiatives. The school counselor, and her teaching colleagues, shared that the presence of these adults increased student motivation and self-efficacy.

Of course, participants also expressed frustration over some of the cultural "realities" they could not control or would expect limited success in altering, namely low levels of Latina/o parents' education ("typically less than a high school education”), inability to influence Latino parental school participation ("some parents are very involved and others, because they work three jobs, can't come in regularly”) and increasing assimilation that contributes to acculturative stress ("there's just so much to learn for Hispanic kids and parents alike, about school, the town, English . . . it's overwhelming”). These concerns are validated in the literature (Hovey \& King, 1996; Pew Hispanic Center, 2005a), and more importantly, are additional considerations for all educators working in rural settings with burgeoning Latina/o communities. Fortunately, participants were united in sharing some hope, partially based on the appreciation many Latina/o families had for school staff, as well as the common goal educators and Latina/o parents share for improving the lives of local Latina/o children.

Though these findings contribute to the literature on the experiences of Latina/o children in rural, burgeoning communities, it must be stated that qualitative studies have an inherent limitation related to generalizations (Krueger, 1998). Consequently, it is not possible based on this study to assume all educators working in burgeoning Latino communities, even those in the Southeastern U.S., share similar ideas. Also, this study lacks comparative information from teachers and school counselors in urban, traditionally Latina/o communities. Finally, it is possible that authors' biases filtered into the data analysis because of their extensive literature review and personal feelings about the lack of information on the academic and personal-social characteristics of Latina/o children in burgeoning communities (Hill et al., 2005).

\section{Conclusion}

All children and parents, Latina/o and non-Latina/o alike, can benefit from the work of teachers, school counselors and school administrators. However, the work done by educators on behalf of students and parents has the potential to be more effective when it takes into account community and family contexts. Participants in this study demonstrated the importance of culture, community and demographic changes by sharing their experiences with Latina/o children and families in their schools. In the process they managed to add some perspective to the academic and personal/social needs and strengths of the burgeoning, local Latino community, in addition to detailing their efforts to assist Latina/o stakeholders in their schools. Perhaps, by considering the findings in this study, other educators working in rural and burgeoning Latino communities can more effectively influence the scholastic experience of their Latino student body.

Acknowledgement

This study was fully funded with a New Faculty Grant from The University of North Carolina at Greensboro (UNCG). The findings, recommendations, and conclusions expressed in this article are those of the authors and do not necessarily reflect the views of UNCG.

\section{References}

August, D., \& Hakuta, K. (Eds.). (1997). Improving schooling for language-minority children: A research agenda. Washington, DC: National Academy Press.

Crawford, J. (1999). Bilingual education: History, politics, theory and practice ( $4^{\text {th }}$ ed.). Los Angeles, CA: Bilingual Educational Services.

Dinsmore, J. A., \& Hess, R. S. (1999). Preparing teachers for diversity in rural America. The Rural Educator, 20, $19-24$

Gopaul-McNicol, S., \& Thomas-Presswood, T. (1998). Working with linguistically and culturally different children: Innovative clinical and educational approaches. Boston, MA: Allyn \& Bacon.

Hamann, E. T., Wortham, S., \& Murillo, E. G. (2002). Education and policy in the new Latino diaspora. In S. Wortham, E. G. Murillo, \& E. T. Hamann (Eds.), Education in the new Latino diaspora. Westport, CT: Ablex Publishing.

Hendrickson, S. M., McCarthy Veach, P., \& LeRoy, B. S. (2002). A qualitative investigation of student and supervisor perceptions of live supervision in genetic counseling. Journal of Genetic Counseling, 11, 25-49.

Hill, C., Knox, S., Thompson, T. J., Williams, E. N., Hess, S., \& Ladany, N. (2005). Consensual qualitative research: An update. Journal of Counseling Psychology, 52, 196-205.

Hill, C. E., Thompson, B. J., \& Williams, E. N. (1997). A guide to conducting consensual qualitative research. The Counseling Psychologist, 25, 517-572.

Hovey, J. D., \& King, C. A. (1996). Acculturative stress, depression, and suicidal ideation among immigrant and second-generation Latino adolescents. Journal of the American Academy of Child Adolescent Psychiatry, 35, 1183-1192.

Krueger, R. A. (1998). Developing questions for focus groups: Focus group kit 3. Thousand Oaks, CA: Sage. 
Livingston, A., \& Wirt, J. (2004). The condition of education 2004. U.S. Department of Education, National Center for Education Statistics. Washington, DC: U.S. Government Printing Office.

Mejia, D. (1983). The development of Mexican-American children. In G. J. Powell, J. Yamamoto, A. Romero, \& A. Morales (Eds.), The psychological development of minority group children (pp. 483-489). New York: Brunner/Mazel.

Martin, B. N. (2001). Meeting the challenge of a changing rural school/community cultural population. The Rural Educator, 22, 1-5.

McCarthy Veach, P., Bartels, D. M., \& LeRoy, B. S. (2001). Ethical and professional challenges posed by patients with genetic concerns: A report of focus group discussions with genetic counselors, physicians, and nurses. Journal of Genetic Counseling, 10, 97-119.

Morgan, D. L. (1997). Focus groups as qualitative research ( $2^{\text {nd }}$ ed.). Thousand Oaks, CA: Sage.

National Center for Education Statistics. (2002). Table by state: School year 2001-2002. Retrieved February 21, 2004, from http://nces.ed.gov/ccd/bat/Result.asp?view=Stateid=691 724285

National Center for Education Statistics. (2003). Overview of public elementary and secondary schools and districts: School year 2001-2002. Retrieved February 21, 2004, from http://www.nces.ed.gov/pubs2003/snf report03/table_01_1.osp
Pew Hispanic Center. (2005a). Hispanics: A people in motion. Washington, D.C.: Author

Pew Hispanic Center. (2005b). The new Latino south: The context and consequences of rapid population growth. Washington, D.C.: Author.

President's Advisory Commission on Educational Excellence for Hispanic Americans (2003). From risk to opportunity: Fulfilling the educational needs of Hispanic Americans in the $21^{\text {st }}$ century. Retrieved February 21, 2004, from http://www.yesican.gov/paceea/final.html

The Education Trust. (2003). Latino achievement in America. Washington, D.C.: Author.

Torres, C. C. (2001, January). Changes in rural America: Producer and community strategies. Paper presented at the annual meeting of the Southern Regional Sociological Association, Fort Worth, TX.

U. S. Census Bureau. (n.d.). North Carolina quick facts. Retrieved September 13, 2004, from http://quickfacts.census.gov/qfd/states/37/37037.html

Wortham, S., \& Contreras, M. (2002). Struggling toward culturally relevant pedagogy in the Latin diaspora. Journal of Latinos and Education, 2, 133-144.

Zea, M., Diehl, J., \& Porterfield, S. (1997). Central American youth exposed to war and violence. In J. G. Garcia \& M. Zea (Eds.), Psychological interventions and research with Latino populations (pp. 39-55). Needham Heights, MA: Allyn \& Bacon. 